\title{
Oblique Fetal Presentation
}

National Cancer Institute

\section{Source}

National Cancer Institute. Oblique Fetal Presentation. NCI Thesaurus. Code C92838.

A fetal position during delivery in which the spine of the fetus is not aligned with the

mother's resulting in the descent into the birth canal in an oblique position. 